\title{
The methodological rigor of anticipatory bioethics
}

\author{
Bert Gordijn · Henk ten Have
}

Published online: 11 June 2014

(C) Springer Science+Business Media Dordrecht 2014

The discipline of historiography, understood as the scientific exploration of the past, has developed much earlier in time than that of futurology, i.e. the methodologically rigorous examination of the future. Yet anticipating the future has arguably always had more practical importance than knowing and understanding the past. Hence anticipation is a crucial aspect of deliberation-the rational reflection on and organization of our action - and indeed ethics. Even in Kantian ethics, with its seemingly utter disregard for the real-world consequences of our actions, anticipating hypothetical future scenarios appears to be an important element of the rational exercise of figuring out whether maxims are universalizable. Even so, the gap between the huge aggregate of rigorous studies of the past and the cautious beginnings of critical analyses and thorough assessments of future scenarios is striking. No surprise then that we know a lot about the past and only very little about the future.

Take technology as an example, arguably one of the contemporary phenomena most significantly reshaping the human condition. There is a colossal amount of knowledge about the history, and indeed the prehistory of technology. Studying the historical and archeological data and looking at the way technology has developed since it started with the use of simple stone tools more than two million years ago, it is hard to resist the impression that the pace of technological innovation overall seems to have been accelerating over time. Indeed, in the Paleolithic

\footnotetext{
B. Gordijn $(\square)$

Dublin, Ireland

e-mail: bert.gordijn@dcu.ie

H. ten Have

Duquesne University, Pittsburgh, USA
}

technological progress must have been a difficult concept to come up with, since nobody would ever witness any significant technological change during his or her lifetime. Today in contrast, many people lament the speed of technological advance. It really does affect everybody, so much so that it sometimes seems difficult to keep up with evernew changes. Understandably, speculation about various new technology-induced vistas of the future is burgeoning.

In the early 1990s Vernor Vinge published his essay on the technological singularity (Vinge 1993). Reflecting on the future of technology he predicted the rise of superhumanly intelligent entities within the next 30 years, explored different scenarios of how this might occur (AI, enhanced human brains etc.) and looked into the potential effects of this development. He argued that the singularity would likely mean a huge acceleration of further technological progress, because innovation would henceforth be driven by powers more intelligent than anything currently known to humans, making many of our present models of reality obsolete (Vinge 1993).

Ray Kurzweil later maintained that the singularity would involve a merger of human beings and technology, and more generally a fierce technological change so much so that it would represent a "rupture in the fabric of human history" (Kurzweil 2005, 9). He even set a date when the singularity would actually occur: the year 2045. Unsurprisingly Vinge's and Kurzweil's ideas have drawn a range of critical reactions pointing out various purported flaws and weaknesses in their respective singularity prognostications.

More recently the singularity debate has gained momentum with two contributions. First in 2012 the Journal of Consciousness Studies published a special double-issue devoted to the singularity (Volume 19, Issue $1-2,2012)$ containing various responses to David Chalmers' philosophical analysis of the idea (Chalmers, 2010). 
Second Eden et al. (2013) published an interesting edited volume, which they hope will move the singularity discussion "beyond the sometimes wild speculations of the blogosphere and promote the growth of singularity studies as a rigorous scholarly discipline" (Eden et al. 2013, 11). Taken together the special double-issue and the edited volume amount to the most rigorous analysis of the notion of the singularity to date, looking at its several components from various philosophical and scientific viewpoints.

Yet it is striking to see how much we know and understand about technology's history, and how little we can solidly discern about its future. This circumstance poses a problem for bioethicists focusing on systematic assessments of emerging technologies within medicine, the life sciences and environmental sciences. If they take an unadulterated historical approach (retrospective bioethics) confining themselves to normative analyses of technological changes after the fact, i.e. after the technologies have been established allowing them to gain enough data about their effects, they certainly avoid speculation. However, in that case their findings risk becoming irrelevant, for their assessments are then emerging too late to inform and influence the regulation of incipient technological developments (Collingridge 1980).

How then should bioethicists cope with this problem? Understandably, they do not wish their reflections to be completely gratuitous in terms of practical impact. However, if they are doing anticipatory bioethics they also wish to be able to distinguish themselves from, for example, science fiction authors who likewise demonstrate a deep interest in the exploration of the moral implications of future technologies. It would be rather depressing, if the only difference were that the latter have by and large better writing skills, produce more attractive books with thoughtprovoking narrative structures and better sales figures. How then can anticipatory bioethicists avoid being panned as bad Sci-Fi writers?

An obvious strategy is to claim that anticipatory bioethics has more methodological rigor than science fiction in its normative exploration of emerging technologies. But can bioethicists really claim this? And if no, how can bioethics' methodological rigor be upgraded?

This is precisely the challenge that Eric Racine et al. (2014) attempt to tackle in the current issue. For the purpose of contextualizing their analysis of anticipatory bioethics the authors zoom in on the discussion on cognitive enhancement. In that debate they distinguish four different sets of assumptions that usually remain implicit and unrecognized. These suppositions pertain to terminology, scientific insights, societal effects and the need for a proactive approach respectively. As these assumptions may skew the discussion in hidden ways, the first step towards a better, anticipatory bioethical examination of cognitive enhancement involves the explicit clarification of these hypotheticals. In addition, Racine et al. recommend a validation of the assumptions by way of sorting out their evidence base in the interdisciplinary scholarly literature, especially empirical studies. Finally, they recommend a broader perspective for the analysis of cognitive enhancement facilitating more across-the-board reflection. With these recommendations they aim to advance methodological rigor in order to improve both the practical significance and the scholarly excellence of anticipatory bioethics (Racine et al. this issue).

\section{References}

Chalmers, D. 2010. The singularity: A philosophical analysis. Journal of Consciousness Studies 17(9-10): 7-65.

Collingridge, D. 1980. The social control of technology. London: Pinter.

Eden, A.H., J.H. Moor, J.H. Soraker, and E. Steinhart. 2013. Singularity hypotheses: A scientific and philosophical assessment. Berlin: Springer.

Kurzweil, R. 2005. The singularity is near: When humans transcend biology. Chicago: Penguin.

Racine, E., T.M. Rubio, J. Chandler, C. Forlini, and J. Lucke. 2014. The value and pitfalls of speculation about science and technology in bioethics: The case of cognitive enhancement (this issue).

Vinge, V. 1993. The coming technological singularity. Whole Earth Review 81: 88-95. 